\title{
Evaluation of simulation training in cardiothoracic surgery: The Senior Tour perspective
}

\author{
James I. Fann, MD, ${ }^{\mathrm{a}}$ Richard H. Feins, MD, ${ }^{\mathrm{b}}$ George L. Hicks, Jr, MD, ${ }^{\mathrm{c}}$ Jonathan C. Nesbitt, MD, \\ John W. Hammon, MD, ${ }^{e}$ Fred A. Crawford, Jr, MD, ${ }^{f}$ and members of the Senior Tour in Cardiothoracic \\ Surgery
}

Objective: The study objective was to introduce senior surgeons, referred to as members of the "Senior Tour," to simulation-based learning and evaluate ongoing simulation efforts in cardiothoracic surgery.

\begin{abstract}
Methods: Thirteen senior cardiothoracic surgeons participated in a 21/2-day Senior Tour Meeting. Of 12 simulators, each participant focused on 6 cardiac (small vessel anastomosis, aortic cannulation, cardiopulmonary bypass, aortic valve replacement, mitral valve repair, and aortic root replacement) or 6 thoracic surgical simulators (hilar dissection, esophageal anastomosis, rigid bronchoscopy, video-assisted thoracoscopic surgery lobectomy, tracheal resection, and sleeve resection). The participants provided critical feedback regarding the realism and utility of the simulators, which served as the basis for a composite assessment of the simulators.
\end{abstract}

Results: All participants acknowledged that simulation may not provide a wholly immersive experience. For small vessel anastomosis, the portable chest model is less realistic compared with the porcine model, but is valuable in teaching anastomosis mechanics. The aortic cannulation model allows multiple cannulations and can serve as a thoracic aortic surgery model. The cardiopulmonary bypass simulator provides crisis management experience. The porcine aortic valve replacement, mitral valve annuloplasty, and aortic root models are realistic and permit standardized training. The hilar dissection model is subject to variability of porcine anatomy and fragility of the vascular structures. The realistic esophageal anastomosis simulator presents various approaches to esophageal anastomosis. The exercise associated with the rigid bronchoscopy model is brief, and adding additional procedures should be considered. The tracheal resection, sleeve resection, and video-assisted thoracoscopic surgery lobectomy models are highly realistic and simulate advanced maneuvers.

Conclusions: By providing the necessary tools, such as task trainers and assessment instruments, the Senior Tour may be one means to enhance simulation-based learning in cardiothoracic surgery. The Senior Tour members can provide regular programmatic evaluation and critical analyses to ensure that proposed simulators are of educational value. (J Thorac Cardiovasc Surg 2012;143:264-72)

Supplemental material is available online.

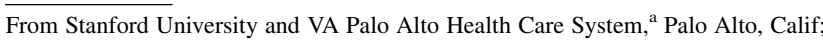
University of North Carolina, ${ }^{\mathrm{b}}$ Chapel Hill, NC; University of Rochester, ${ }^{\mathrm{c}}$ Rochester, NY; Vanderbilt University, ${ }^{\mathrm{d}}$ Nashville, Tenn; Wake Forest School of Medicine, ${ }^{\mathrm{e}}$ Winston-Salem, NC; and Medical University of South Carolina, ${ }^{\mathrm{f}}$ Charleston, SC.

This study was supported by the Thoracic Surgery Directors Association and the Joint Council for Thoracic Surgery Education, the Thoracic Surgery Foundation for Research and Education Simulation Grant (J.I.F. and R.H.F.), and the Western Thoracic Surgical Association Doty Award (J.I.F.). Corporate sponsors of this session included the Chamberlain Group, Sorin Group, Cryolife, Inc, St Jude Medical, Teleflex Medical, and Lifelike BioTissue.

Disclosures: Authors have nothing to disclose with regard to commercial support. Members of the Senior Tour in Cardiothoracic Surgery: James A. Alexander, MD, Fred A. Crawford, Jr, MD, Thomas M. Daniel, MD, L. Penfield Faber, MD, John W. Hammon, MD, Kamal A. Mansour, MD, William F. Northrup III, MD, D. Glenn Pennington, MD, Bruce A. Reitz, MD, W. Steves Ring, MD, Norman J. Snow, MD, Donald C. Watson, MD, and Walter G. Wolfe, MD.

Received for publication April 27, 2011; revisions received July 27, 2011; accepted for publication Oct 4, 2011; available ahead of print Nov 11, 2011.

Address for reprints: James I. Fann, MD, Department of Cardiothoracic Surgery, Stanford University, 300 Pasteur Drive, Stanford, CA 94305 (E-mail: jfann@ stanford.edu).

0022-5223/\$0.00

Published by Elsevier Inc. on behalf of The American Association for Thoracic Surgery doi:10.1016/j.jtcvs.2011.10.013
Patient safety concerns, changes in resident education, and more complex procedures in high-risk patients have generated greater interest in simulation-based learning in cardiothoracic surgical training. ${ }^{1-12}$ Surgical simulation permits the resident to interact in a less stressful environment and may provide structured graduated training of technical skills and crisis management. Furthermore, educators recognize this modality as one method by which proficiency may be assessed. ${ }^{13-17}$ As a means to stimulate and evaluate simulation in cardiothoracic surgery and under the auspices of the Thoracic Surgery Directors Association and the Joint Council on Thoracic Surgery Education, national efforts have included the "Boot Camp," a 3-day training session for first-year cardiothoracic surgery residents, and recently the "Senior Tour," composed of senior cardiothoracic surgical educators. ${ }^{3,5,12}$ On the basis of novel simulators and focused practice, the emphasis at the Boot Camp has been on 5 components of training, including (1) cardiopulmonary bypass and cannulation, (2) coronary anastomosis, (3) pulmonary resection, (4) bronchoscopy and mediastinoscopy, and (5) aortic valve surgery. Concurrent with these efforts has 


\section{Abbreviations and Acronyms \\ VATS $=$ video-assisted thoracoscopic surgery}

been the development of cardiothoracic surgical simulators at many academic centers. ${ }^{2,3,6-9,11,18}$

Despite the progress to date, educational and logistic concerns of cardiothoracic surgery simulation training remain. Identified barriers to adoption include but are not limited to faculty time and commitment, facility cost, cost of equipment and supplies, need for support personnel, trainee's time away from clinical activity, identification of representative simulators, definition of comprehensive curriculum and assessment, and, perhaps the most challenging, organizational "buy-in." To increase the group of expert educators in training residents and to potentially disseminate novel training methods to residency programs were the bases of the Senior Tour. The intent of the initial Senior Tour session is to introduce the members to simulation-based learning and to provide them with an opportunity to train residents using these modalities. Also, in the development of new educational techniques, it is critically important to regularly evaluate proposed projects. The Senior Tour members may provide valuable feedback regarding the utility and impact of these simulators, address barriers and constraints to adoption, and explore possible solutions. This much needed evaluation of simulation-based learning in cardiothoracic surgery serves as the basis of this report.

\section{MATERIALS AND METHODS}

Thirteen senior cardiothoracic surgeons participated in a $2 \frac{1}{2}-$-day Senior Tour Meeting at the Cardiothoracic Surgery Simulation Center at the University of North Carolina Medical School, Chapel Hill. At the meeting, lectures included essential concepts of simulation and performance assessment, description of simulators, proposed cost, various constraints to the adoption of simulation, and the concept of deliberate practice. Experts from the military, aviation, and electronic game industry discussed training and development of simulation-based learning in their respective fields. The simulation center comprises a class room, 12 simulation rooms with audio-visual recording capability, and a simulator preparation room. Two rooms were used for each simulation exercise. Each room was equipped with 1 surgical simulator (see below), lighting, surgical instruments, and sutures. Surgical gowns and gloves were provided, and loupe magnification, if necessary, was used by the participants. Approval was obtained from the institutional review board at the University of North Carolina to review and analyze the information from this educational activity.

\section{Protocol and Simulators}

The Senior Tour members were divided into 2 groups: one focused on cardiac and one focused on thoracic surgery. On day 1 , each member was allotted 1.5 hours to become familiar with 3 simulators that the member later used to train 3 general surgery residents individually with formative feedback during hands-on, practical sessions each lasting 40 minutes (Table 1). A total of 9 general surgery residents participated. On day 2, each was allotted 1.5 hours to become familiar with 3 more advanced simulators, which he used to train 3 cardiothoracic surgery residents individu- ally with formative feedback in 40-minute sessions. A total of 7 cardiothoracic surgery residents participated. On day 3, the Senior Tour members met as a group to provide critical feedback regarding the realism and utility of each simulator, identify methods to improve the training exercises, address constraints to simulation-based learning, and define the process of starting simulation programs. Along with simulator development, rating scales for performance assessment based on the Objective Structured Assessment of Technical Skills were developed for 9 simulators; the intent of the rating scales was to provide a framework for performance assessment (Appendix E1). ${ }^{15}$ The following is a list of simulators developed by the program participants and others that were used at the Senior Tour meeting. ${ }^{2,3,5,6,8,9,18}$

1. Small vessel anastomosis: Mounted in the portable chest model (HeartCase, Chamberlain Group, Great Barrington, Mass) are 3- to 4-mm synthetic target vessels; to simulate vein graft for the anastomosis, 3- to 4-mm synthetic vessels are used (Figure 1, $A$ ). The anastomoses are performed using 5-0 polypropylene sutures. For the tissue-based or "wet-lab" component, porcine hearts are prepared and positioned to expose the left anterior descending artery in a container (WetLab, LTD, Kenilworth, Warwicks, England) as previously described. ${ }^{3}$ Expired cryopreserved saphenous veins (Cryolife, Inc, Kennesaw, Ga) and synthetic tissue grafts (LifeLike BioTissue, Toronto, Ontario) are used as grafts for the anastomosis using 6-0 polypropylene sutures.

2. Aortic cannulation: A porcine descending thoracic aorta is prepared by oversewing the intercostal vessels and securing it in a plastic thoracic model. The aorta is cannulated and connected via intravenous tubing to a pressurized bag of saline (Figure 1, B). The pressurized ascending aorta allows placement of 3-0 polyester pursestring sutures followed by placement of aortic cannula; because of the long length of the aorta of the model, multiple cannulations using a variety of cannulae are performed.

3. Cardiopulmonary bypass: The perfusion simulator is an interactive simulator used in the training of perfusionists and surgeons and has been described (Figure 1,C). ${ }^{5}$ The plastic container with a porcine heart model and inflow and outflow lines are part of the simulator. The system simulates multiple physiologic and pharmacologic conditions and permits the trainee to manage the steps preceding and during cardiopulmonary bypass, including requirements for instituting and weaning from cardiopulmonary bypass and crisis management.

4. Hilar dissection: A porcine heart-lung block placed within the chest cavity of a mannequin simulates the necessary maneuvers of hilar dissection through a thoracotomy incision (Figure 2, A). Either the right or left lung is used. This exercise replicates the confined thoracic space in which pulmonary resections are performed and provides a method to practice hilar dissection skills. The objectives are to identify anatomic landmarks noting anatomic variants, dissect and encircle the hilar vessels and bronchus, and ligate and divide vascular structures.

5. Esophageal anastomosis: A porcine heart-lung-esophagus block simulates the thoracotomy incision providing access to the posterior mediastinum (Figure 2,B). The esophagus, positioned and secured in the posterior cavity, is isolated and transected. The 2 free ends are reapproximated in 1 or 2 layers. This model permits the alignment and approximation of the esophageal ends, the proper placement of sutures within the esophageal wall, and the sutures to be secured after placement. This model also permits the use of stapling devices.

6. Rigid bronchoscopy: With the use of conventional bronchoscopic equipment, the Trucorp AirSim simulator (Belfast, North Ireland) is a model of the oral pharynx, the larynx, and the tracheobronchial tree out to the segmental anatomy (Figure 2, C). The model also allows simulation of awake bronchoscopy, bronchial stent placement, and removal of foreign body.

7. Aortic valve replacement: For the tissue-based aortic valve replacement simulation, explanted porcine hearts are placed in the container (WetLab, LTD) and situated to present the ascending aorta and aortic 
TABLE 1. Senior Tour program schedule

Day 1:

Lectures:

Essentials of simulator-based education

Deliberate practice in cardiothoracic surgery training

Simulation training in the military

Overview of and hands-on training using basic skills simulators:

Cardiac:

Small vessel anastomosis

Aortic cannulation

Cardiopulmonary bypass

Thoracic:

Hilar dissection

Esophageal anastomosis

Rigid bronchoscopy

Day 2:

Lectures:

Introducing simulator-based training into training programs

Cost of cardiothoracic surgery simulation

Facility needs

Importance of briefing and debriefing

Simulation in the game industry

Overview of and hands-on training using more advanced simulators:

Cardiac:

Aortic valve replacement

Mitral valve repair

Aortic root replacement

Thoracic:

Videoscopically-assisted (VATS) lobectomy

Tracheal resection

Sleeve resection

Day 3:

Program review:

Evaluation of simulators

Discussion of logistic and adoption issues

root (Figure 3, A). The aortotomy is made followed by excision of the leaflets and the muscle bar under the right coronary cusp. Interrupted polyester sutures are placed followed by the placement and seating of the valve prosthesis (St Jude Medical, St Paul, Minn).

8. Mitral valve repair: The synthetic mitral valve model is a silicone-based cylinder placed in a portable chest model (HeartCase, Chamberlain Group) (Figure 3,B). The model is pliable, which permits some degree of traction during suture placement. For the tissue-based simulator, explanted porcine hearts are placed in the container (WetLab, LTD) and situated to present the left atrium and mitral annular plane. The left atrium is opened, and stay sutures are placed to expose the mitral valve and annulus in an "anatomically correct" configuration (Figure 3,B). Interrupted polyester annular sutures are placed, and an annuloplasty ring (Sorin Group, Arvada, Colo) is situated and secured.

9. Aortic root replacement: For the tissue-based aortic root replacement simulator, explanted porcine hearts are placed in the container (WetLab, LTD) and situated to present the ascending aorta and aortic root. The porcine aorta and root are resected after creation of the coronary ostial buttons. An aortic homograft (Cryolife, Inc) is prepared and anastomosed as a root replacement using polypropylene sutures for coronary button reimplantation (Figure 3,C).

10. Video-assisted thoracoscopic surgery (VATS) lobectomy: A left porcine heart-lung block placed within the chest cavity of a mannequin is accessed via fixed working ports to allow video-assisted resection (Figure 4, A). The exercise replicates the confined thoracic space in which pulmonary resections are performed and provided a model to practice hilar dissection and resection skills. This simulator allows for identifying anatomic landmarks, maneuvering the thoracoscope and pulmonary structures, dissecting and encircling hilar vessels and bronchus, and dividing the structures using the endoscopic staplers. This model does not permit different port placement.

11. Tracheal resection: A porcine tracheal-esophageal segment placed within the open neck of a mannequin simulates tracheal resection and anastomosis (Figure 4, B). This exercise reproduces the confined space in which tracheal resections are performed and provides a model to practice such resection and anastomosis.

12. Sleeve resection: A porcine heart-lung block placed within the chest cavity of a mannequin simulates the necessary maneuvers of sleeve resection via a thoracotomy (Figure $4, C$ ). This exercise replicates the confined thoracic space in which sleeve resections are performed.

\section{Resident and Faculty Evaluation}

After completion of the protocol, the resident and Senior Tour participants were asked to complete an evaluation of 5 simulators (aortic valve replacement, mitral annuloplasty, hilar dissection, esophageal anastomosis, and VATS lobectomy). The questionnaire (based on a 3-point scale) was focused on the participants' opinions regarding the realism of the simulator, whether it stressed important components, and the value of the simulator in training technical skills. The data are reported as mean \pm standard deviation. Findings from the questionnaires were combined with the Senior Tour members' discussions and evaluations on day 3 to form a composite assessment of all simulators.

\section{RESULTS}

\section{General Evaluation}

All participants acknowledged that the simulation environment may not provide a wholly immersive experience, particularly when using task trainers with limited space, equipment, and personnel. To improve the educational session, adequate time must be allotted for orienting residents, defining objectives and expectations, providing formative feedback, and briefing and debriefing. On the basis of the educators' experience, it is important to spend time with the residents to understand their knowledge base and what skills they bring to the simulation experience. In addition, it may be valuable for residents to have video-based instruction by experts using each simulator for orientation and ongoing practice and to define objectives for technical skills development. The following are evaluation summaries of the simulators.

1. Small vessel anastomosis: The portable thoracic chest model with synthetic grafts and target vessel offers some degree of realism, but its importance is in teaching the mechanics of anastomosis; however, the synthetic material is less realistic in terms of tissue handling. The porcine heart with saphenous vein anastomosis provides a high degree of realism.

2. Aortic cannulation: The porcine aortic model has a moderate degree of realism. The tissue-handling properties are realistic, and multiple cannulations can 

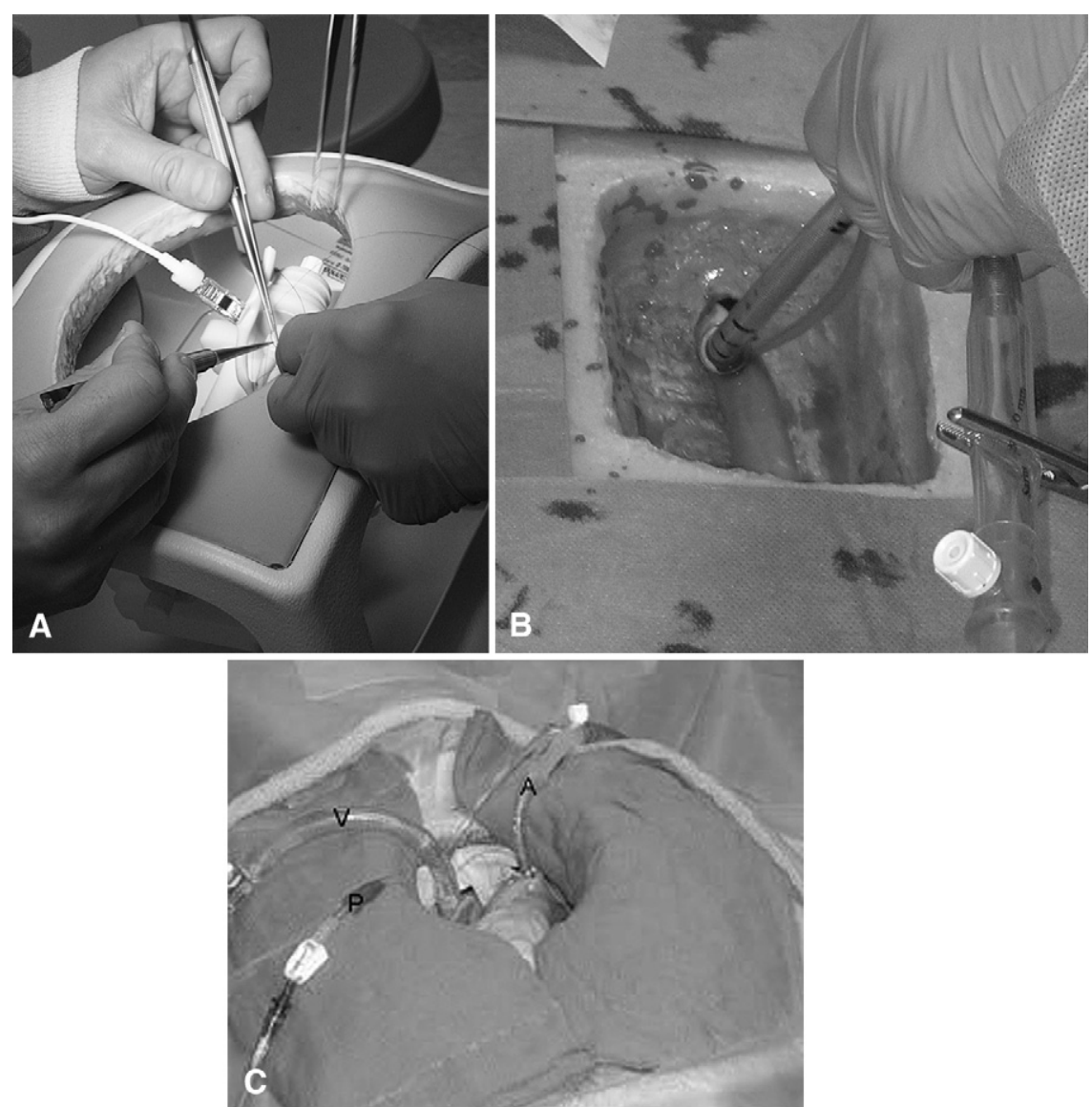

FIGURE 1. A, Small vessel anastomosis: Mounted in the portable chest model are synthetic target vessels; to simulate vein graft for the anastomosis, synthetic vessels are used. For the tissue-based or "wet-laboratory" component, porcine hearts are prepared and positioned to expose the left anterior descending artery in a container. B, Aortic cannulation: A porcine descending thoracic aorta is secured in a plastic thoracic model. The pressurized ascending aorta allows placement of purse-string sutures followed by placement of aortic cannula; because of the length of aorta, multiple cannulations are performed. C, Cardiopulmonary bypass: The plastic container with a porcine heart model and inflow and outflow lines are part of the simulator. The system simulates multiple physiologic conditions during cardiopulmonary bypass. $A$, Aortic cannula; $V$, atrial cannula; $P$, cardioplegia line.
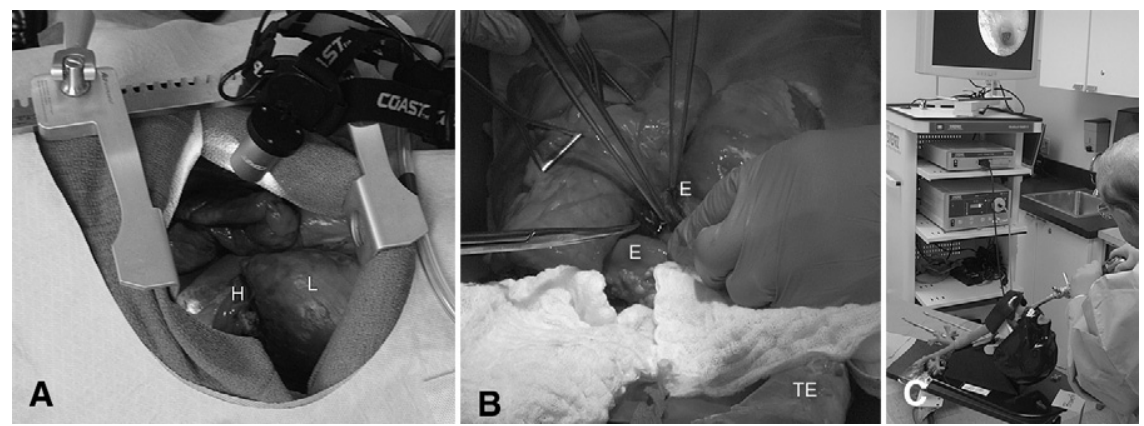

FIGURE 2. A, Hilar dissection: A porcine heart-lung block placed within the chest cavity of a mannequin simulates the necessary maneuvers of hilar dissection through a thoracotomy incision. B, Esophageal anastomosis: A porcine heart-lung-esophagus block simulates the thoracotomy incision providing access to the posterior mediastinum. The esophagus is isolated, transected, and reapproximated in 1 or 2 layers. C, Rigid bronchoscopy: By using conventional bronchoscopic equipment, the Trucorp AirSim model (Belfast, North Ireland) simulates the tracheobronchial tree. $L$, Lung; $H$, hilum; $E$, esophagus; $T E$, tracheoesophageal segment. 

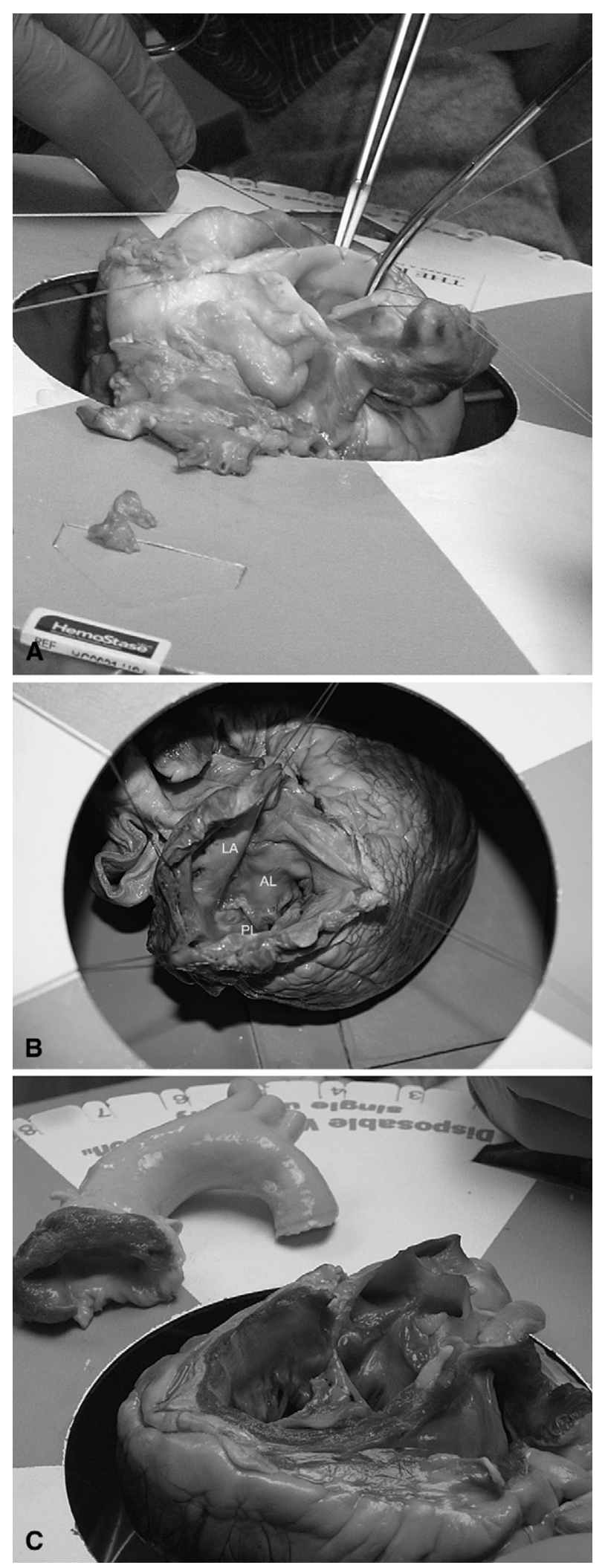

FIGURE 3. A, Aortic valve replacement: For the tissue-based aortic valve replacement simulator, porcine hearts are placed in the container and situated to present the ascending aorta and aortic root. The aortotomy is made be performed using this model. It can also serve as a thoracic aortic surgery anastomosis model.

3. Cardiopulmonary bypass: The simulator provides a realistic experience; however, given the complexity of this simulator, more time is needed to optimize the crisis management experience.

4. Hilar dissection: This tissue-based model has a moderate degree of realism recognizing the variability of porcine anatomy relative to human anatomy and the fragility of the vascular structures. Although the intent of this exercise is to isolate the vessels and bronchus, this exercise can be extended to vessel ligation and lobectomy. The time required for this exercise is greater than the time allotted.

5. Esophageal anastomosis: This tissue-based porcine simulator is highly realistic in presenting various approaches to esophageal anastomosis, particularly in regard to 1- and 2-layer anastomotic techniques. Placed within a thoracic mannequin, this model can be extended to include the stomach to simulate esophagogastric anastomosis. Also, providing and resolving tension can be introduced, and creating longitudinal incision (with longer mucosal than muscular incision) would simulate esophageal rupture, requiring the trainee to perform appropriate repair.

6. Rigid bronchoscopy: This plastic simulator is highly realistic, but this exercise is brief, and adding additional levels of complexity, such as foreign body removal and airway stenting, should be considered.

7. Aortic valve replacement: This tissue-based model is often used in "wet-laboratory" settings and is highly realistic but does require more time than allotted. This model lends itself to standardized training, as it is currently used in many centers.

8. Mitral valve annuloplasty: The synthetic model provides a method to learn basic components of mitral valve surgery, such as exposure techniques and needle angles, but it is limited in its fidelity. The porcine model is realistic but posed some challenges with anteriorposterior orientation in the set-up. Also, it provides an idealized exposure, which is not always appreciated in the clinical setting, but it should be possible to increase the degree of difficulty by altering the exposure,

followed by excision of the leaflets and implantation of the aortic valve. B, Mitral valve repair: The synthetic mitral valve model is placed in a portable chest model. For the tissue-based simulator, porcine hearts are placed in the container and situated to present the mitral valve. The left atrium is retracted to expose the mitral valve and annuloplasty performed. C, Aortic root replacement: For the tissue-based aortic root replacement simulator, porcine hearts are placed in the container. The porcine aorta and root are resected after creation of the coronary ostial buttons. An aortic homograft is anastomosed as a root replacement. $L A$, Left atrial wall; $A L$, anterior leaflet; $P L$, posterior leaflet. 

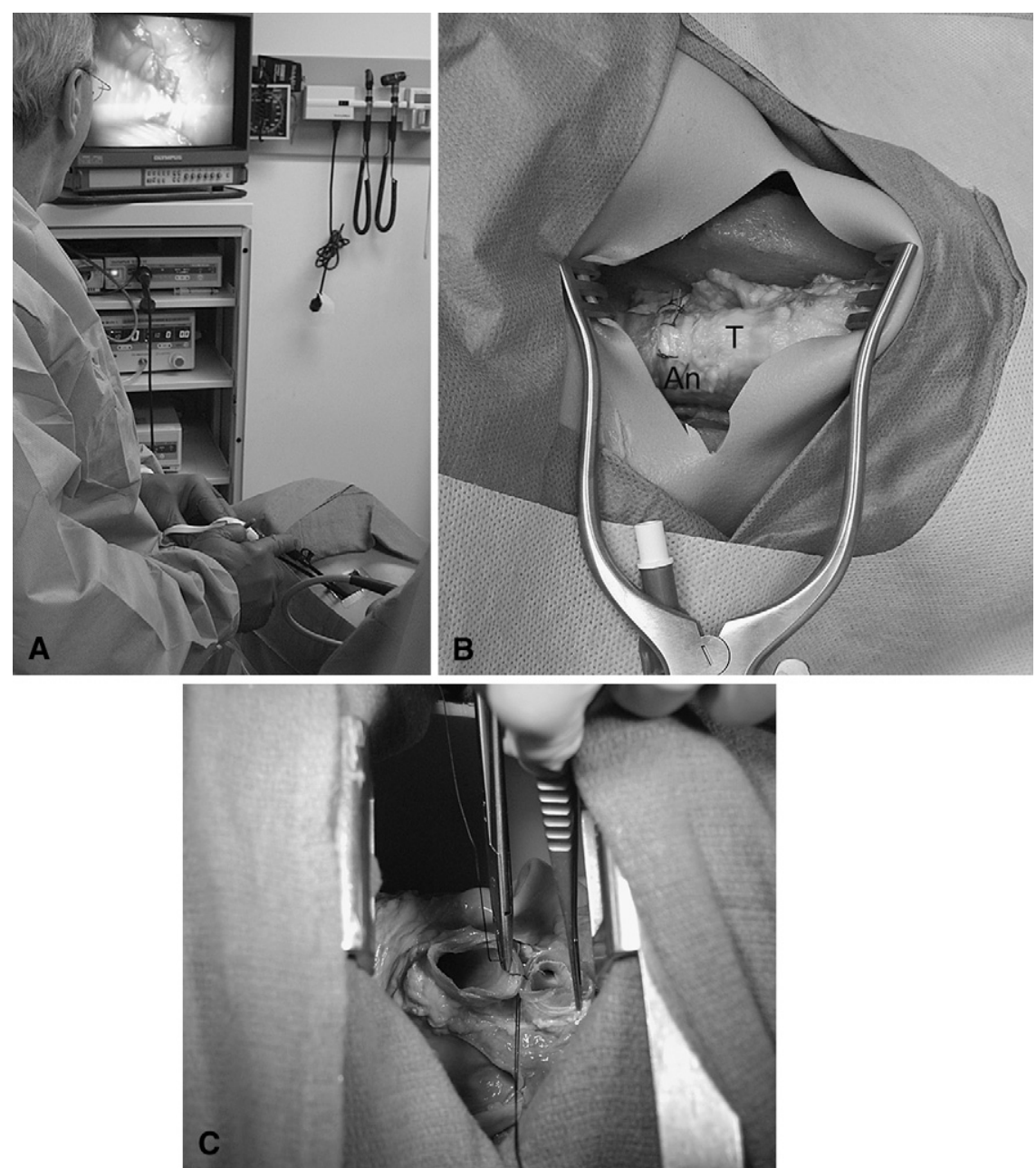

FIGURE 4. A, VATS lobectomy: A left porcine heart-lung block placed within the chest cavity of a mannequin is accessed via working ports to allow for video-assisted resection. B, Tracheal resection: A porcine tracheal-esophageal segment placed within the open neck of a mannequin simulates tracheal resection and anastomosis. C, Sleeve resection: A porcine heart-lung block placed within the chest cavity of a mannequin (similar to the hilar dissection model) simulates the necessary maneuvers of sleeve resection. $T$, Trachea; An, anastomosis.

as was discussed during the briefing period. The leaflets are retracted in the porcine model; releasing the papillary-chordal attachments permits some degree of leaflet prolapse.

9. Aortic root replacement: This tissue-based model is highly realistic with a high level of complexity. Although the session was limited in time at this session, the basic resection and implantation of coronary buttons can be accomplished. The complete procedure requires a longer period of time to complete.

10. VATS lobectomy: This tissue-based model is highly realistic and of moderate to high level of complexity. The port sites can be optimized to enhance training. By recognizing interspecies differences, this model may be more complex than a case in the clinical setting, but it does provide simulation of many advanced maneuvers. This exercise requires more time than allotted in this session.
11. Tracheal resection: This tissue-based model has a reasonable degree of realism. Given the shorter period of time required for this exercise, additional procedures (eg, tracheostomy and tracheal release maneuvers) can be added.

12. Sleeve resection: This tissue-based model is highly realistic and permits airway mobilization and comprehension of the principles of bronchial anastomosis.

\section{Resident and Senior Tour Participant Evaluation}

In general, most believed that the simulators provided a reasonably realistic experience and were valuable in teaching technical skills. Although these simulators stressed important concepts of a certain task, they do not fully simulate the clinical operative experience. The responses of the written questionnaires of 5 simulators are shown in Table 2. The findings and comments from the 
TABLE 2. Evaluation of 5 simulators used at the Senior Tour

\begin{tabular}{|c|c|c|c|c|c|}
\hline & $\begin{array}{l}\text { Hilar dissection } \\
\quad(\mathbf{n}=\mathbf{1 0})\end{array}$ & $\begin{array}{c}\text { AVR } \\
(\mathbf{n}=\mathbf{1 0})\end{array}$ & $\begin{array}{l}\text { MV repair } \\
(\mathbf{n}=\mathbf{1 0})\end{array}$ & $\begin{array}{l}\text { Esophageal anastomosis } \\
\qquad(\mathrm{n}=7)\end{array}$ & $\begin{array}{l}\text { VATS lobectomy } \\
\quad(\mathbf{n}=\mathbf{5})\end{array}$ \\
\hline The simulator was realistic & $2.7 \pm 0.7$ & 3 & $2.6 \pm 0.7$ & $2.9 \pm 0.4$ & $2.6 \pm 0.6$ \\
\hline The simulator stressed important skills & $2.7 \pm 0.7$ & 3 & 3 & 3 & $2.8 \pm 0.5$ \\
\hline $\begin{array}{l}\text { Performing the skill using the simulator was as } \\
\text { real as in the operating room }\end{array}$ & $2.4 \pm 0.7$ & $2 \pm 0.9$ & $2.4 \pm 0.7$ & $2.6 \pm 0.5$ & $2.2 \pm 0.5$ \\
\hline The simulator is a good method of skills training & $2.8 \pm 0.6$ & 3 & 3 & 3 & $2.8 \pm 0.5$ \\
\hline
\end{tabular}

Score: $3=$ agree; $2=$ neutral; $1=$ disagree. Data are presented as mean $\pm \mathrm{SD}$. AVR, Aortic valve replacement; $M V$, mitral valve; VATS, video-assisted thoracoscopic surgery.

questionnaires combined with Senior Tour evaluations on day 3 of the session formed the composite assessment (Table 3). The rating scales for performance assessment (Appendix E1) were considered generally useful; the anchoring points (ie, what each number of the 5-point Likert scale represents) were not sufficient, and additional refinements will be necessary.

\section{DISCUSSION}

Because simulated skills training has been proposed as an approach to provide graduated training and enhance resident performance in cardiothoracic surgery, ${ }^{1-3,5,6,8-11,18}$ the Senior Tour may be one means to increase the number of expert educators and potentially disseminate simulation-based learning to cardiothoracic surgery programs. By providing the necessary tools, such as task trainers and assessment instruments, Senior Tour members can assist in initiating surgical simulation efforts and providing regular programmatic evaluation to ensure that proposed simulators are of value. This critical analysis conducted by the Senior Tour faculty noted that many simulators can be improved and the intended task and assessment better defined.
Having appropriate model fidelity for trainees of different abilities may optimize the effectiveness of simulation training. ${ }^{19,20}$ The simulators assessed at the Senior Tour are of varying fidelity; some are less realistic, such as the synthetic anastomosis task stations, and others are highly realistic, such as the esophageal anastomosis and aortic valve replacement. Nonetheless, the realism of a simulator must be placed in the context of the intent of the simulation exercise. Studies on model fidelity and educational effectiveness have shown that a low-fidelity bench model conferred the same degree of benefit as training on a high-fidelity model in certain procedures. ${ }^{19,21}$ Because skills acquired on low-fidelity bench models transfer to improved performance on higher-fidelity models, some have suggested that such simulation may improve performance in the operating room. ${ }^{13,16,22-24}$ In general, tissuebased simulators are more realistic, especially when the objectives are defined, such as identifying anatomic landmarks, learning to suture in deep cavities, and ligating vascular structures. Although the porcine model does provide good tactile feedback, it still may not be representative of the human lung or heart. For instance, the anatomic landmarks of the porcine heart model are realistic, whereas

TABLE 3. Summary evaluation of simulators used at the Senior Tour

\begin{tabular}{|c|c|c|c|c|c|c|}
\hline & $\begin{array}{c}\text { Time required } \\
\text { to set up }\end{array}$ & $\begin{array}{l}\text { Time required } \\
\text { to complete }\end{array}$ & $\begin{array}{l}\text { Complexity } \\
\text { of simulator }\end{array}$ & $\begin{array}{c}\text { Degree of } \\
\text { perceived realism }\end{array}$ & $\begin{array}{c}\text { Stressed important } \\
\text { technical skills }\end{array}$ & $\begin{array}{c}\text { Compared with } \\
\text { operative experience }\end{array}$ \\
\hline \multicolumn{7}{|l|}{ Small vessel anastomosis } \\
\hline Synthetic & + & + & + & + & $+H$ & + \\
\hline Tissue-based & + & + & + & $H+$ & $H+$ & + \\
\hline Aortic cannulation & + & + & + & $H$ & H & $H$ \\
\hline Cardiopulmonary bypass & + & $+H$ & $H+$ & $H+$ & $H+$ & $H+$ \\
\hline Hilar dissection & ++ & ++ & ++ & $+H$ & $+H$ & + \\
\hline Esophageal anastomosis & $H$ & $H$ & $H$ & $H+$ & $H+$ & $H$ \\
\hline Rigid bronchoscopy & + & + & $H$ & + & $H+$ & $H$ \\
\hline Aortic valve replacement & + & + & + & $H+$ & $H+$ & $H$ \\
\hline \multicolumn{7}{|l|}{ Mitral valve repair } \\
\hline Synthetic & + & + & + & + & + & + \\
\hline Tissue-based & $H$ & H & + & $H$ & $H+$ & $H$ \\
\hline Aortic root replacement & + & $+H$ & + & $H+$ & $H+$ & $H+$ \\
\hline VATS lobectomy & $H$ & + & $H$ & $H$ & $H+$ & $+H$ \\
\hline Tracheal resection & ++ & ++ & + & + & + & + \\
\hline Sleeve resection & + & + & + & + & + & + \\
\hline
\end{tabular}


for the lung model, the hilar structures show interspecies differences that need to be resolved. From a practical perspective, for surgical educators intending to incorporate laboratory-based surgical skills training into the curriculum, a reasonable strategy would be to begin by having novice trainees learn on a low-fidelity bench model that captures the key constructs of the surgical task; once proficient, the trainee can then progress in a graduated manner to practice on models of higher fidelity. ${ }^{3,19}$ Thus, one can use both low- and high-fidelity task stations, which emphasize the technical components of procedure and provide greater realism as the trainee advances. Whether improved performance in the simulation laboratory is transferable to the operating room is not easily addressed; further evaluation is necessary, recognizing that operating room performance depends not only on technical skill but also on cognitive integration, judgment, and interactions among team members. ${ }^{3}$

Important, unresolved issues include achieving faculty and institutional buy-in of surgical simulation. Clearly, without a commitment from the leadership, this educational endeavor will not be implemented. For simulation-based learning to be successful and widely adopted, compensation for participating faculty and faculty development at local academic centers need to be better defined. Junior faculty engaged in resident education and simulation development should be acknowledged in the promotion process, and activities related to education need to be perceived as representing real value in one's academic career. ${ }^{3}$ The cost of simulation-based learning, both in equipment and faculty time, must be recognized at the institutional and national levels so that initial and ongoing funds are available. In regard to the logistics of establishing a simulation center, cardiothoracic surgery training programs should consider partnering with the existing general surgical simulation laboratory at the local institution. Collaborative efforts with other disciplines, such as anesthesiology and vascular surgery, can result in an enhanced educational endeavor.

Courses that teach and assess a surgical skill are vitally important in identifying those trainees requiring remediation. On the basis of other domains of expertise and expert performance, teaching or "coaching" in the simulation laboratory by a skilled surgical educator is a critical element of deliberate practice, so that formative feedback and defining areas of weakness requiring further practice or remediation can be carried out. ${ }^{14,25}$ Furthermore, for the resident to improve his/her technical skills, defined practice periods in a simulation laboratory and at home are critically necessary. On the basis of the learning principle of massed practice (or practice with no rest) versus distributed practice (or practice interspersed with rest) in many domains, distributed practice leads to better skill acquisition and retention. ${ }^{2,26,27}$ Thus, an important component of simulation-based training is to provide training in the principles and methods of surgical education along with the use of simulators. A valuable program established last year by the Joint Council on Thoracic Surgery Education is the Educate the Educator course, modeled after the Surgeons as Educators course organized by the American College of Surgeons. ${ }^{28,29}$ Along with the Educate the Educator course, the Senior Tour members can provide an important means to enhance educational training to the faculty in the cardiothoracic surgery residency programs.

Depending on the extent of previous training and surgical experience, which may vary greatly in current training programs, residents at the same training level may be at different proficiency levels, and simulation-based learning is one means to assess proficiency. A fundamental assessment tool is the Objective Structured Assessment of Technical Skills, which includes a task-specific checklist and a global rating scale. ${ }^{14-17,26}$ Reliable assessment tools of technical and nontechnical skills are paramount if simulation is to be universally adopted and applied to proficiency-based advancement. Proposed rating scales for performance assessment created for the simulators used at the Senior Tour (Appendix E1) provide a framework and will require further modifications, including comprehensive anchoring, as the simulation efforts progress. To date, performance assessment in cardiothoracic surgery simulation has been reported for coronary anastomosis, cardiopulmonary bypass, mitral valve surgery, and pulmonary surgery. ${ }^{2,3,5,8,9}$ In addition, one proposal is to define tasks to be mastered, such as coronary anastomosis and airway management, that are considered essential for advancement in a training program. Such tasks, which may be performed and assessed using simulators, can form the basis of the development of Fundamentals of Cardiothoracic Surgery, an analogue of the Fundamentals of Laparoscopic Surgery course used in general surgery training. However, before one can carry out a potential mandate of requiring simulation-based learning at all institutions, there have to be well-defined simulators that are considered reasonably valid with reliable assessment.

\section{CONCLUSIONS}

The Senior Tour may be one means to enhance simulation-based learning in cardiothoracic surgery. The critical analysis by the Senior Tour members can improve simulator development and assist in better defining the intended task to be trained. Current simulators in cardiothoracic surgery vary in fidelity; although tissue-based simulators provide good tactile feedback, they still may not be fully representative of the human lung or heart. One important focus to improve simulation efforts has been to establish a structured technical skills curriculum. Proposed rating scales for performance assessment created for simulators used at the Senior Tour will need to 
be evaluated for reliability and modifications, such as comprehensive anchoring points, made as the simulation efforts progress.

The authors thank Beth Winer for assistance in the organization of this program; the surgery residents for participation and evaluation of the simulators; and Jose Piscoya and Jewel Sheehan for assistance in preparing and setting up the simulators.

\section{References}

1. Carpenter AJ, Yang SC, Uhlig PN, Colson YL. Envisioning simulation in the future of thoracic surgical education. J Thorac Cardiovasc Surg. 2008;135:477-84.

2. Fann JI, Caffarelli AD, Georgette G, Howard SK, Gaba DM, Youngblood P, et al. Improvement in coronary anastomosis with cardiac surgery simulation. J Thorac Cardiovasc Surg. 2008;136:1486-91.

3. Fann JI, Calhoon JH, Carpenter AJ, Merrill WH, Brown JW, Poston RS, et al. Simulation in coronary artery anastomosis early in cardiothoracic surgical residency training: the Boot Camp experience. J Thorac Cardiovasc Surg. 2010;139: 1275-81.

4. Feins RH. Expert commentary: cardiothoracic surgical simulation. J Thorac Cardiovasc Surg. 2008;135:485-6.

5. Hicks GL Jr, Gangemi J, Angona RE Jr, Ramphal PS, Feins RH, Fann JI. Cardiopulmonary bypass simulation at the Boot Camp. J Thorac Cardiovasc Surg. 2011;141:284-92.

6. Tesche LJ, Feins RH, Dedmon MM, Newton KN, Egan TM, Haithcock BE, et al. Simulation experience enhances medical students' interest in cardiothoracic surgery. Ann Thorac Surg. 2010;90:1967-74.

7. Ramphal PS, Coore DN, Craven MP, Forbes NF, Newman SM, Coye AA, et al. A high fidelity tissue-based cardiac surgical simulator. Eur J Cardiothorac Surg. 2005;27:910-6.

8. Carter YM, Marshall MB. Open lobectomy simulator is an effective tool for teaching thoracic surgical skills. Ann Thorac Surg. 2009;87:1546-50.

9. Joyce DL, Dhillon TS, Caffarelli AD, Joyce DD, Tsirigotis DN, Burdon TA, et al. Simulation and skills training in mitral valve surgery. J Thorac Cardiovasc Surg. 2011;141:107-12.

10. Lodge D, Grantcharov T. Training and assessment of technical skills and competency in cardiac surgery. Eur J Cardiothorac Surg. 2011;39:287-93.

11. Solomon B, Bizekis C, Dellis SL, Donington JS, Oliker A, Balsam LB, et al. Simulating video-assisted thoracoscopic lobectomy: a virtual reality cognitive task simulation. J Thorac Cardiovasc Surg. 2011;141:249-55.

12. Hicks GL Jr, Brown JW, Calhoon JH, Merrill WH. You never know unless you try. J Thorac Cardiovasc Surg. 2008;136:814-5.
13. Palter VN, Grantcharov T, Harvey A, Macrae HM. Ex vivo technical skills training transfers to the operating room and enhances cognitive learning: a randomized controlled trial. Ann Surg. 2011;253:886-9.

14. Reznick RK, MacRae H. Teaching surgical skills—changes in the wind. N Engl J Med. 2006;355:2664-9.

15. Reznick R, Regehr G, MacRae H, Martin J, McCulloch W. Testing technical skill via an innovative "bench station" examination. Am J Surg. 1996;172:226-30.

16. Beard JD, Jolly BC, Newbie DI, Thomas WEG, Donnelly TJ, Southgate LJ. Assessing the technical skills of surgical trainees. Br J Surg. 2005;92:778-82.

17. Martin JA, Regehr G, Reznick R, MacRae H, Murnaghan J, Hutchison C, et al. Objective structured assessment of technical skill (OSATS) for surgical residents. Br J Surg. 1997;84:273-8.

18. Schiralli MP, Hicks GL, Angona RE, Gangemi JJ. An inexpensive cardiac bypass cannulation simulator: facing challenges of modern training. Ann Thorac Surg. 2010;89:2056-7.

19. Grober ED, Hamstra SJ, Wanzel KR, Reznick RK, Matsumoto ED, Sidhu RS, et al. The educational impact of bench model fidelity on the acquisition of technical skill. Ann Surg. 2004;240:374-81.

20. Sidhu RS, Park J, Brydges R, MacRae HM, Dubrowski A. Laboratory-based vascular anastomosis training: a randomized controlled trial evaluating the effects of bench model fidelity and level of training on skill acquisition. J Vasc Surg. 2007; 45:343-9.

21. Anastakis DJ, Regehr G, Reznick RK, Cusimano M, Murnaghan J, Brown M, et al. Assessment of technical skills transfer from the bench training model to the human model. Am J Surg. 1999;177:167-70.

22. Datta V, Bann S, Beard J, Mandalia M, Darzi A. Comparison of bench test evaluations of surgical skill with live operating performance assessments. J Am Coll Surg. 2004;199:603-6.

23. Grantcharov TP, Kristiansen VB, Bendix J, Bardram L, Rosenberg J, FunchJensen R. Randomized clinical trial of virtual reality simulation for laparoscopic skills training. Br J Surg. 2004;91:146-50.

24. Seymour NE, Gallagher AG, Roman SA, O'Brien MK, Bansal VK, Andersen DK, et al. Virtual reality training improves operating room performance. Ann Surg. 2002;236:458-64.

25. Ericsson KA, Krampe RT, Tesch-Romer C. The role of deliberate practice in the acquisition of expert performance. Psychol Rev. 1993;100:363-406.

26. Moulton CA, Dubrowski A, MacRae H, Graham B, Grober E, Reznick R. Teaching surgical skills: what kind of practice makes perfect? Ann Surg. 2006;244: 400-9.

27. Donovan JJ, Radosevich DJ. A meta-analytic review of the distribution of practice effect: now you see it, now you don't. J Appl Psychol. 1999;84:795-805.

28. Verrier ED. Joint Council on Thoracic Surgical Education: an investment in our future. J Thorac Cardiovasc Surg. 2011;141:318-21.

29. Surgeons as Educators course. Available at: http://www.facs.org/education/sre/ saeintro.html. Accessed October 12, 2011. 
APPENDIX E1. Sample assessment forms

CORONARY ARTERY ANASTOMOSIS ASSESSMENT

RESIDENT NAME

EVALUATOR
YR OF TRAINING TIME TO COMPLETION

\section{Arteriotomy}

(porcine model: able to identify target, proper use of blade, single groove, centered)

2. Graft orientation

(proper orientation for toe-heel, appropriate start and end points)

\section{Bite appropriate}

(entry and exit points, number of punctures, even and consistent distance from edge)

\section{Spacing appropriate}

(even spacing, consistent distance from previous bite, too close vs too far)

\section{Use of Castroviejo/Jacobson needle holder}

(finger placement, instrument rotation, facility, needle placement, pronation and supination, proper finger and hand motion, lack of wrist motion)

\section{Use of forceps}

(facility, hand motion, assist needle placement, appropriate traction on tissue)

\section{Needle angles}

(proper angle relative to tissue and needle holder, consider depth of field, anticipating subsequent angles)

\section{Needle transfer}

(needle placement and preparation from stitch to stitch, use of instrument, and hand to mount needle)

\section{Suture management/tension}

(too loose vs tight, use tension to assist exposure, avoid entanglement)

Definitions:

5. Excellent, able to accomplish goal without hesitation, showing excellent progress and flow

4. Good, able to accomplish goal deliberately, with minimal hesitation, showing good progress and flow

3. Average, able to accomplish goal with hesitation, discontinuous progress and flow

2. Below average, able to partially accomplish goal with hesitation

1. Poor, unable to accomplish goal; marked hesitation

(modified from Fann JI, Caffarelli AD, Georgette G, Howard SK, Gaba DM, Youngblood P, et al. Improvement in coronary anastomosis with cardiac surgery simulation.J Thorac Cardiovasc Surg. 2008;136:1486-91)

\begin{tabular}{|c|c|c|}
\hline Poor & & Average \\
\hline 1 & 2 & 3 \\
\hline
\end{tabular}

$\begin{array}{lllll}1 & 2 & 3 & 4 & 5\end{array}$

$\begin{array}{lllll}1 & 2 & 3 & 4 & 5\end{array}$

$\begin{array}{lllll}1 & 2 & 3 & 4 & 5\end{array}$

$\begin{array}{lllll}1 & 2 & 3 & 4 & 5\end{array}$




\section{AORTIC CANNULATION ASSESSMENT}

RESIDENT NAME
EVALUATOR

YR OF TRAINING

1. Assess aorta for suture placement/cannulation

(palpate aorta, assess for calcification, ensure

adequate blood pressure for suture placement)

2. Needle angles

(proper angle to permit needle point to puncture tissue; consider depth of field, limits of access, and space constraints)

3. Needle removal from aorta

(follow curve of the needle to minimize tissue trauma)

\section{Depth of bite}

(proper and consistent depth of entry and exit points of needle and suture)

5. Suture advance and spacing (proper distance of suture travel in aorta, even spacing; consistent distance from previous bite)

6. Control of scalpel

(proper orientation relative to aorta;

proper size of aortotomy)

7. Cannula placement

(proper orientation of bevel; hold close to tip, proper insertion depth)

\section{Securing cannula and knot-tying}

(adequate tension, facility; proper finger and hand movements to secure knots, not too loose or tight)
Poor

1

DATE

\begin{tabular}{lllll} 
Poor & & \multicolumn{2}{l}{ Average } & Excel \\
1 & 2 & 3 & 4 & 5
\end{tabular}

1

2

3

4

5

$\begin{array}{lllll}1 & 2 & 3 & 4 & 5\end{array}$

1

2

3

4

5 1

2

3

4

5

1

2

3

4

5

1

2

3

4

5

Definitions:

5. Excellent, able to accomplish goal without hesitation, showing excellent progress and flow

4. Good, able to accomplish goal deliberately, with minimal hesitation, showing good progress and flow

3. Average, able to accomplish goal with hesitation, discontinuous progress and flow

2. Below average, able to partially accomplish goal with hesitation

1. Poor, unable to accomplish goal; marked hesitation 


\section{CARDIOPULMONARY BYPASS ASSESSMENT}

RESIDENT NAME

EVALUATOR

Steps

Initiation:

Ensure adequate activated clotting time

Communicate with perfusionist

Check line pressure

Assess venous drainage

Vent placement

Cardioplegia

Crossclamp

Termination:

Removal of cross-clamp

Deairing procedures

Vent removal

Weaning CPB:

Ventilator is on

Temperature satisfactory

TEE to assess intracardiac air

TEE to assess cardiac function

No bleeding in inaccessible areas

Acceptable rhythm / pacing wires Need for inotropic support

Termination of bypass

Decannulation
YR OF TRAINING

DATE

Satisfactory Comments
$\mathrm{Y} \quad \mathrm{N}$

$\mathrm{Y} \quad \mathrm{N}$

Y N

Y N

Y N

$\mathrm{Y} \quad \mathrm{N}$

$\mathrm{Y} \quad \mathrm{N}$

$\begin{array}{ll}Y & N \\ Y & N \\ Y & N \\ & \\ Y & N \\ Y & N \\ Y & N \\ Y & N \\ Y & N \\ Y & N \\ Y & N \\ Y & N \\ Y & N\end{array}$

Economy of time 1

and motion 1 = many unnecessary/ disorganized movements
2

$3=$ organized time/motion, some unnecessary movement

\section{5}

$5=$ maximum economy of movement and efficiency

Final rating (circle one)

Demonstrates competence

Needs further practice

Additional comments:

$C P B$, Cardiopulmonary bypass; TEE, transesophageal echocardiography (from Hicks GL Jr, et al. Cardiopulmonary bypass simulation and assessment at the Boot Camp. J Thorac Cardiovasc Surg. 2011;141:284) 


\section{AORTIC VALVE REPLACEMENT ASSESSMENT}

RESIDENT NAME EVALUATOR
YR OF TRAINING

1. Make aortotomy and stay suture placement

(oblique or transverse; deliberate and controlled; use of scalpel and scissors; appropriate location and depth of stay sutures)

\section{Excise aortic leaflets}

(identify leaflet hinge points; avoid injury to annulus; decalcification and debridement discussed but not assessed if using model)

\section{Sizing annulus}

(use sizer appropriately and understand valve size selection)

\section{Needle angles}

(proper angle to permit needle point to puncture tissue;

consider depth of field, limits of access, and space constraints)

5. Needle removal from annulus

(follow curve of the needle to minimize tissue trauma)

\section{Tissue handling}

(gentle manipulation without excessive tension and tissue trauma)

\section{Depth of bite}

(proper and consistent depth of entry and exit points of needle and suture)

\section{Suture advance along annulus}

(proper distance of suture travel in annulus, not too small or large)

\section{Spacing between sutures}

(even spacing; consistent distance from previous bite, not too close or too far)

\section{Suture management/tension}

(avoid entanglement; use tension and traction to assist exposure)

\section{Situating aortic valve prosthesis}

(proper orientation relative to the annulus; proper suture placement from edge; suture spacing proportionate to annulus)

\section{Knot-tying}

(adequate tension, facility; proper finger and hand movements to secure knots, not too loose or tight)

\section{Definitions:}

5. Excellent, able to accomplish goal without hesitation, showing excellent progress and flow

4. Good, able to accomplish goal deliberately, with minimal hesitation, showing good progress and flow

3. Average, able to accomplish goal with hesitation, discontinuous progress and flow

2. Below average, able to partially accomplish goal with hesitation

1. Poor, unable to accomplish goal; marked hesitation
DATE

\begin{tabular}{lllll} 
Poor & & \multicolumn{2}{l}{ Average } & Excel \\
1 & 2 & 3 & 4 & 5
\end{tabular}

1

1

1

1

1

1

1

1

2

3

5

2

5

5

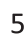
5 5 5

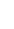
5 
MITRAL VALVE REPAIR ASSESSMENT

RESIDENT NAME EVALUATOR
YR OF TRAINING DATE

ATPR

1. Identify posterior mitral annulus

(demonstrate annulus, ie, decussation or junction of leaflet and atrial wall, for suture placement)

\section{Identify anterior mitral annulus}

(demonstrate annulus, ie, junction of leaflet and fibroskeleton, for suture placement)

\section{Needle angles}

(proper angle to permit needle point to puncture orthogonal to tissue plane; consider depth of field, and space constraints)

4. Needle removal from annulus

(follow curve of the needle to minimize tissue trauma)

\section{Tissue handling}

(gentle manipulation without excessive tension and tissue trauma)

\section{Depth of bite}

(proper depth of entry and exit points; proper and consistent depth of needle and suture)

\section{Suture advance along annulus}

(proper distance of suture travel in annulus, not too small or large)

\section{Spacing between sutures}

(even spacing; consistent distance from previous bite, not too close or too far)

\section{Situating mitral ring}

(proper orientation relative to the annulus; proper suture placement from edge; proper suture spacing)

\section{Knot-tying}

(adequate tension, facility; follow for finger and hand

to secure knots, not too loose or tight)

\section{Suture management/tension}

(avoid entanglement; use tension and traction to assist exposure)

1

1
Poor

1

1

2

Average

Excel

2

3

4

5

2

2

3

45

2

3

4

5

2

(
3

45

Definitions:

5. Excellent, able to accomplish goal without hesitation, showing excellent progress and flow

4. Good, able to accomplish goal deliberately, with minimal hesitation, showing good progress and flow

3. Average, able to accomplish goal with hesitation, discontinuous progress and flow

2. Below average, able to partially accomplish goal with hesitation

1. Poor, unable to accomplish goal; marked hesitation

(from Joyce DL, et al. Simulation and skills training in mitral valve surgery. J Thorac

Cardiovasc Surg. 2011;141:107-12) 
PULMONARY HILAR DISSECTION ASSESSMENT

RESIDENT NAME EVALUATOR YR OF TRAINING DATE
Poor
1. Tissue Handling
1
2
Clumsy, forceful grasping
2. Time and Motion
1
Many unnecessary moves

3. Instrument Use

1

Awkward and uncoordinated

4. Knowledge of Anatomy 1 Little to no knowledge

5. Dissection, separation

Unable to accomplish without undue structural damage

6. Ligation and tying 1 Unable to perform 2

Final rating (circle one)

1 (poor)

2

2

2

2

2

Ser

Separated structures excess tissue
Careful handling of tissue with occasional mishandling

\section{Average}

Excel

$\begin{array}{ll} & 3 \\ \text { Efficient time, but some } & 4 \\ \text { unnecessary moves }\end{array}$

4

unnecessary moves

34

Occasional awkwardness, relatively competent

4 5

Consistent gentle handling of tissue with coordinated grasping

\section{5}

Fluid and efficient economy of motion

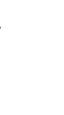

Coordinated and competent

\section{5}

Moderate level of knowledge, Well-versed in anatomy no knowledge of variants and variants

4

Successful structure isolation without injuries

$$
3
$$

4

Slow with hesitation, but successful

5

Competent tying skills

3(fair)

4

5 (competent) 


\section{ESOPHAGEAL ANASTOMOSIS ASSESSMENT}

RESIDENT NAME

YR OF TRAINING

EVALUATOR

Poor

1. Structure Orientation Poorly aligned, uneven approximation

2. Tissue Handling Clumsy, forceful grasping

3. Time and Motion 1 Many unnecessary moves

2 Many unnecessary moves

4. Instrument Use

1

Awkward and not coordinated

5. Needle Angles

1

Consistently poor position of angle relative to needle holder and tissue

2 2

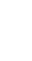

Careful tissue handling with occasional mishandling

Moderately well-aligned, able to compensate proximity

3
Careful tissue handling
with occasional mishandling

$\quad 3$
Efficient time, but some
unnecessary moves

3
Occasional awkwardness,
moderately competent

3
Fair positioning of angle
relative to needle holde
and tissue
3
Fair bite depth and
spacing
$\quad 3$
Slow with hesitation,
but successful
6. Suture Placement

\section{2}
Poor and inconsistent bite
depth and spacing

7. Ligation and Tying

Final rating (circle one) : $\quad 1$ (poor)

2
1

Unable to perform

2

but successful
4

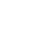

\section{Good positioning of} angle relative to needle and tissue handling with coordinated grasping

\section{Fluid and efficient}

economy of motion

Coordinated and

competent

5
Consistent and even
bite depth and spacing

Consistent gentle tissue

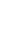

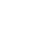

\author{
5
}

Competent tying skills

$$
\text { 3(fair) }
$$

4
Well-aligned throughout anastomosis of structures

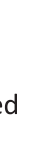




\section{THORACOSCOPIC LOBECTOMY ASSESSMENT}

RESIDENT NAME

EVALUATOR

$\begin{array}{cc} & \text { Poor } \\ \text { 1. Tissue Handling } & 1\end{array}$

2. Time and Motion (lung and scope)

1

Many unnecessary moves

1

Awkward and not coordinated

4. Dissection and Isolation of Structures

1

Unable to accomplish without undue structural damage

5. Ligation and Tying 1

Unable to perform

2

(1)

2
YR OF TRAINING

DATE
Average

3

Careful tissue handling with occasional mishandling

3

Efficient time use, but some unnecessary moves$$
\text { Unable to perform }
$$

\section{Occasional awkwardness, moderately competent}

3
Separated structures with
occasional injury and excess
tissue
$\quad 3$
Slow with hesitation,
but successful

4

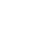
Consistent gentle tissue
handling with coordinated grasping

5

Fluid and efficient economy of motion

\begin{tabular}{l}
\multicolumn{1}{c}{5} \\
Coordinated and \\
competent \\
\multicolumn{1}{c}{5} \\
Successful structure \\
isolation without \\
injuries \\
$\quad 5$ \\
Competent tying skills
\end{tabular}

Final rating (circle one) : $\quad 1$ (poor) 3(fair)

4
Excel 


\section{BRONCHOSCOPY}

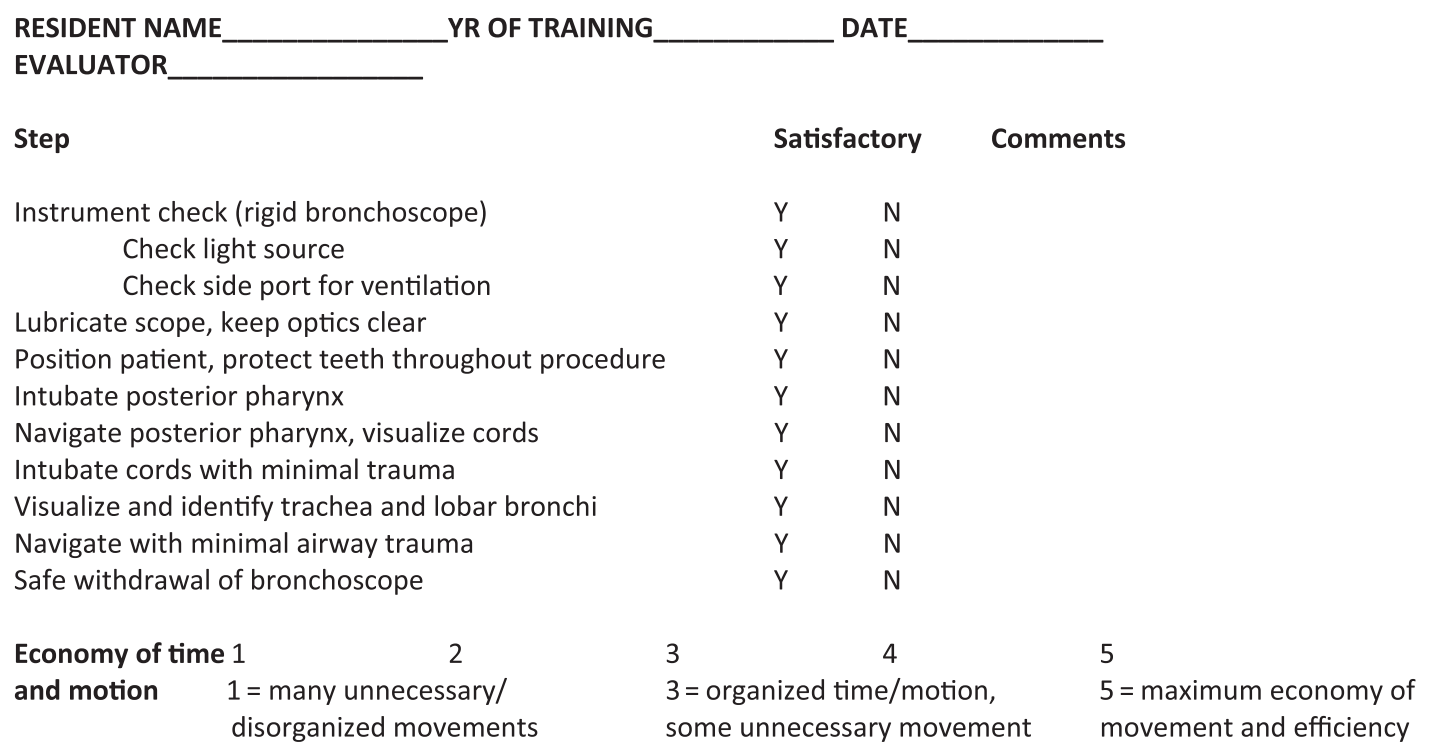

Final rating (circle one) Demonstrates competence Needs further practice

Additional comments:

(from Ara Vaporciyan, MD, personal communication, 2009; format modified from Verification of

Proficiency, Southern Illinois University) 